\title{
Mimesis, dúvida e poder: divindades hindus e espíritos de colonizadores na Guiana
}

Mimesis, doubt and power: Hindu deities and spirits of colonizers in Guyana

\author{
Marcelo Moura Mello* \\ *Universidade Federal da Bahia - Salvador, BA, Brasil \\ mmmello@gmail.com \\ https://orcid.org/0000-0002-9460-2824
}




\title{
Resumo
}

Por meio da descrição das interações entre espíritos de colonizadores, especialistas religiosos, divindades e devotos da deusa hindu Kali na Guiana, o artigo busca demonstrar como concepções nativas sobre a presença de entes espirituais no mundo são atravessadas por dúvidas, hesitações e (re)elaborações retrospectivas de eventos passados, bem como por reflexões aguçadas sobre as potencialidades de seres com estatutos ontológicos distintos assumirem, incorporarem e imitarem atributos e poderes de outros seres.

Palavras-chave: culto a Kali; dúvida; possessão espiritual; Guiana.

\begin{abstract}
Through the description of the interactions between spirits of colonizers, religious specialists, deities and devotees of the Hindu goddess Kali in Guyana, the article aims to demonstrate how native conceptions about the presence of spiritual beings in the world are crossed by doubts, hesitations and retrospective (re)elaborations of past events, as well as for reflections on the potentialities of beings with distinct ontological statutes to assume, incorporate and imitate the attributes and powers of other beings.
\end{abstract}

Keywords: Kali worship; doubt; spiritual possession; Guyana. 


\section{Introdução ${ }^{1}$}

Descrições sobre a possessão espiritual de missionários, viajantes, literatos e agentes coloniais em épocas passadas, ou de cientistas sociais nas últimas décadas, produziram análises permeadas pela fascinação, ou mesmo incredulidade, suscitadas pelas diferenças canalizadas por meio de atos corporais e discursivos - gestos e performances de entes espirituais nos corpos de outros manifestariam crenças no sobrenatural. Para além de perceber o caráter exterior das representações ocidentais sobre a possessão espiritual, marcadas pelo exotismo e pela primitivização, diversos estudos chamaram a atenção para o fato de que o exotismo de europeus foi incorporado pelos outros em diversos níveis, desde o artístico até o de rituais marcados pela possessão espiritual e pelo xamanismo (ver, dentre outros, as distintas perspectivas de Johnson, 2011; Kramer, 1993; Romberg, 2014; Severi, 2000; Stoller, 1995; Taussig, 1987, 1993).

Neste artigo descrevo as interações e as relações entre espíritos de colonizadores europeus e membros de uma vertente hindu existente na Guiana, o culto à deusa hindu Kali. No culto a Kali rituais de cura são conduzidos semanalmente por meio de divindades hindus que realizam tratamentos terapêuticos em pessoas que enfrentam problemas pessoais e de saúde, muitos dos quais causados por espíritos. Busco compreender menos como membros do culto a Kali, em sua maioria de origem indiana, representam colonizadores europeus, e mais os modos pelos quais as ações e os efeitos de entes espirituais (como divindades e espíritos) são conhecidos e reconhecidos em interações concretas, que são marcadas por dúvidas e hesitações. Para tanto, inspiro-me em estudos clássicos e contemporâneos sobre a possessão espiritual.

As arrebatadoras imagens capturadas por Jean Rouch em Os mestres loucos revelam de modo particularmente sensível a fascinação e o terror que as imagens de indivíduos possuídos por outros podem suscitar. Interessado nas relações de africanos com a vida moderna, o espaço urbano e a migração, Rouch

1 Agradecimentos: o material empírico aqui apresentado resulta de pesquisas de campo financiadas pelo Programa de Pós-Graduação em Antropologia Social do Museu Nacional, Universidade Federal do Rio de Janeiro, por meio de recursos da Coordenação de Aperfeiçoamento do Pessoal de Nível Superior (Capes), e pela Universidade Federal da Bahia (Edital PROPCI/Propesq - Programa de Apoio a Jovens Professores Doutores). Agradeço a essas instituições, bem como a pareceristas anônimos(as) de Horizontes Antropológicos, que ajudaram a qualificar esse texto. 
alterna imagens dos Hauka e de cerimoniais dos colonizadores ingleses, produzindo uma compreensão do que é exótico mediante o exagero das semelhanças (cf. Gonçalves, 2008). A narração de Rouch, por sua vez, refaz o sentido do ritual. A cópia de hierarquias coloniais e a reencenação de cerimônias militares pelos Hauka retratam europeus em sua excentricidade. Possuídos por europeus, os Songhay mimetizam o homem branco e adquirem poderes que produzem efeitos corporais potentes, transgredindo e quebrando tabus, fazendo coisas fora do comum. Estranhos europeus, de fato (cf. Taussig, 1993, p. 240-241). Ao incorporar a alteridade de europeus em seus rituais, os Songhay buscam exercer algum controle sobre o próprio fervor descontrolado do poderio europeu. Em situações como essas, não se trata somente de representar a diferença e o exotismo de europeus, mas também de incorporar, canalizar e transgredir poderes simultaneamente perigosos e cativantes. Rituais não estão confinados à expressão de cosmologias cerradas em si mesmas. A alteridade corporificada de europeus aponta para natureza dialógica e assimétrica dos encontros coloniais.

Em sua proposta de destacar a dimensão sensível da etnografia e da análise antropológica, supostamente relegada a um segundo plano por conta de ênfases intelectualistas e a-históricas da disciplina, Paul Stoller $(1989,1995,1997)$ pretende oferecer novas contribuições teóricas por meio do estudo da possessão espiritual. Para Stoller (1995), o corpo senciente está imerso em um mundo repleto de sons, forças, cheiros, texturas, olhares e gostos que acionam memórias sociais. O poder da memória coletiva não emerge, meramente, de inscrições textuais. Em sua proposta, o estudo da possessão espiritual move-se de considerações abstratas sobre como textos rituais constituem discursos para a análise de como práticas incorporadas concretas moldam contextos. A reflexão detida sobre práticas incorporadas como a possessão espiritual permite refletir não apenas sobre sistemas cosmológicos cerrados e estáveis, incluso sobre práticas historiográficas nativas, como bem ilustra o canônico filme de Rouch (Stoller, 1995).

Foge ao escopo desse artigo analisar em profundidade a contribuição crítica e o legado de Os mestres loucos. ${ }^{2}$ Antes, objetivo reter, em um primeiro movimento analítico, o fato de que processos históricos marcados por mudanças

2 Dentre a vasta produção sobre Rouch, ver, dentre outros, Caixeta de Queiroz (2004); Freire (2010); Gonçalves (2008, 2009); Stoller (1992); Sztutman (2005, 2009); Taussig (1993, p. 241-244). 
dramáticas e por atos violentos podem ser rememorados - e, mais importante, incorporados - por conexões miméticas que evocam o passado colonial em suas reverberações no presente. Dito em outros termos, a possessão espiritual pode ser repleta de referentes históricos críticos (Johnson, 2011; Romberg, 2014; Stoller, 1995; Taussig, 1993). Ao mesmo tempo, a conexão entre aquilo que colonizadores brancos simbolizam e a rememoração de conflitos históricos violentos não é evidente. Como demonstrou Severi (2000, p. 127) para o caso dos Kuna, o Homem Branco não necessariamente simboliza apenas poder, mas simultaneamente incerteza, ansiedade, sofrimento mental e mesmo loucura. Em contextos rituais, a recordação ritual do passado anda lado a lado com uma reconfiguração do domínio espiritual.

Neste artigo me ocuparei de espíritos de colonizadores holandeses na Guiana, antiga Guiana Inglesa. Mais especificamente, tratarei das relações entre devotos(as $)^{3}$ da deusa hindu Kali, divindades e espíritos holandeses, seres responsáveis por causar uma série de doenças e aflições entre membros e frequentadores dos templos de Kali. Espíritos holandeses originaram-se, segundo uma narrativa muito difundida na Guiana, após as disputas entre colonizadores holandeses e britânicos, ${ }^{4}$ nos primeiros anos do século XIX. Nos conflitos com britânicos, famílias inteiras de holandeses teriam se suicidado para escapar de assassinatos brutais. Despossuídos de riquezas, terras, bens e propriedades, os holandeses também não receberam serviços fúnebres adequados. A índole dos antigos colonizadores em vida, marcada pelo ímpeto de enriquecer às custas de pessoas escravizadas, conjugada às suas terríveis mortes, imprimiram uma marca indelével na paisagem guianense: os principais locais de moradia desses espíritos são, até hoje, as antigas plantações de açúcar onde viveram no passado.

3 Neste artigo grifo em itálico os termos nativos, quando de sua primeira ocorrência. A depender da situação, insiro, entre colchetes, os termos originais, de modo a explicitar minhas escolhas de tradução.

4 As três regiões que compõe a Guiana - Essequibo, Demerara e Berbice - eram colônias holandesas até o início do século XIX, período no qual britânicos assumiram o controle administrativo e territorial da região. A unificação das três regiões se deu em 1831, dando origem à Guiana Inglesa. A independência dos britânicos sucedeu em 1966, quando o país passou a se chamar Guiana (Guyana). 
Espíritos holandeses são, em seu ponto de vista e no de guianenses da região costeira do país, ${ }^{5}$ os verdadeiros senhores da terra [masters of the land], detendo prerrogativas sobre os locais onde se estabeleceram no passado. Tais prerrogativas revelam-se na predileção desses seres por possuir e atacar pessoas que vivem nesses locais, causando-lhes transtornos por desejos de vingança. Não raro, os espíritos - tanto de holandeses quanto de holandesas - surgem nos sonhos de homens e de mulheres para atacar-lhes sexualmente, provocando-lhes doenças, confusões mentais, desejos desmedidos, como compulsão por bebidas alcoólicas e libido aflorada, além de precipitarem suicídios - a Guiana tem, aliás, uma das maiores taxas de suicídio per capita do mundo, segundo a Organização Mundial de Saúde.

Nesse cenário, diversas pessoas, em sua maioria indo-guianenses, mas também afro-guianenses, buscam o auxílio de sacerdotes e de divindades hindus nos templos de Kali para se curarem das aflições causadas por esses espíritos, ou então para mitigar seus efeitos. Nos templos de Kali não é incomum a intrusão dos espíritos holandeses nas sessões rituais, pois esses seres têm outra característica: a mimetização de divindades hindus. Ou seja, os espíritos se fazem passar por deuses e deusas hindus para causar distúrbios, atestar seu poder e expressar seus pontos de vista. Esses espíritos podem, eventualmente, trabalhar a favor das pessoas, oferecendo conselhos e trazendo recompensas materiais para quem lhes faz ofertas em âmbito doméstico. Engajar-se com espíritos holandeses, entretanto, é algo arriscado, na medida em que eles são essencialmente traiçoeiros e egoístas, propensos a gerar confusões e dúvidas nas pessoas - algo evidenciado, para meus interlocutores, pelas tentativas desses seres de se passarem por divindades hindus.

Uma vez que as descrições de que disponho sobre espíritos de colonizadores não estão apartadas das dinâmicas rituais hindus, tratarei inicialmente dos modos como os efeitos da agência de entes espirituais (particularmente divindades e espíritos dos mortos) são conhecidos, reconhecidos e interpretados (cf.

5 Ressalto que essa visão é corriqueira na região costeira da Guiana. Não sugiro, portanto, que distintos grupos ameríndios, que em sua maioria residem no interior do país, compartilhem esse ponto de vista. Ainda está para ser feito um balanço mais detalhado sobre as distintas concepções de autoctonia e soberania sobre a terra entre grupos ameríndios residentes na Guiana e guianenses da região costeira do país. Ver, entretanto, Mentore (2018) sobre socialidades ameríndias e relações com mortos na Guiana. 
Wirtz, 2014) no culto a Kali, debruçando-me sobre a noção de manifestação. As qualidades perceptivas de ações corporais, atos verbais, discursos, narrativas e a manipulação de artefatos rituais ${ }^{6}$ podem figurar como índices da presença de entes espirituais e de seus efeitos no mundo (cf. Blanes; Espírito Santo, 2014; Keane, 2008). Assim, e como notaram com precisão Blanes e Espírito Santo (2014, p. 17), cabe atentar sob quais circunstâncias entes espirituais se manifestam, são interpretados e tornam-se objetos e sujeitos no mundo, que tipos de eventos ou experiências são tomados como índices válidos ou uma causa primária da agência espiritual e que modos de raciocínio, ou sistemas de inferência, são necessários para que esses entes venham a existir. Ao mesmo tempo, levar a sério a realidade êmica da possessão espiritual implica aceitar, também, as dúvidas, suspeições e acusações acerca da veracidade, simulação e autenticidade acerca dos eventos de possessão (Romberg, 2014). Tal perspectiva é relevante para o caso aqui em pauta pelo fato de meus interlocutores expressarem, reiteradamente, atitudes céticas quanto à genuinidade das manifestações de deuses e deusas hindus em humanos.

O material empírico aqui analisado foi coligido durante pesquisa de campo entre devotos e devotas do templo de Blairmont, localizado na parte ocidental da região de Berbice. Por dez meses, entre 2010 e 2012, observei e participei dos ritos semanais no templo, além de acompanhar trabalhos realizados em âmbito doméstico.7 Informações complementares foram obtidas em curtas saídas de campo levadas a cabo em junho e setembro-outubro de 2018. Nessas ocasiões pude observar não apenas aquilo que era feito em ações rituais específicas, como também envolver-me em conversas nas quais visões, e versões, retrospectivas de eventos passados ganhavam contorno por meio da confrontação e sobreposição de distintos pontos de vista.

6 Como demonstrei alhures (Mello, 2018), murtis, isto é, formas esculpidas de divindades, são fundamentais para se reconhecer dos sinais que permitem inferir qual divindade está se manifestando em um humano.

7 Tais trabalhos [work] são conduzidos por sacerdotes, acompanhados de assistentes, nas casas de devotos(as), sempre em virtude das recomendações expressas por divindades nos templos de Kali. Trabalhos em âmbito doméstico envolvem desde a realização de family, ou ground, pujas (isto é, ofertas para deuses ou deusas cultuadas por famílias) até práticas para aplacar a ação de espíritos ou os efeitos de feitiços. 


\section{Manifestação no culto à deusa hindu Kali}

Transplantado para a Guiana por indianos e indianas que se deslocaram para o país na condição de trabalhadores contratados [indentured labourers] entre 1838 e 1917, após a abolição da escravidão negra no Caribe Britânico em $1834,{ }^{8}$ o culto a Kali [Kali worship ou Kali puja] caracteriza-se por práticas de cura de doenças de origem física e espiritual. Semanalmente, divindades [deotas] hindus se manifestam nos corpos de especialistas religiosos para conduzir tratamentos terapêuticos, ocasiões nas quais revelam, por meio de atos verbais, as causas dos problemas que afligem as pessoas, bem como prescrevem atos de devoção a serem performados para solucionar tais problemas. Os ritos do culto a Kali são denominados pujas, ou seja, as manifestações de crença e submissão às divindades hindus por meio de preces, reverências e oferendas. Eventualmente, trabalhos são realizados em âmbito doméstico (ver nota 7).

No templo onde conduzi a maior parte de minhas observações, Blairmont, 17 deotas (divindades) hindus são cultuadas, seis das quais se manifestam em seus veículos humanos com mais frequência. O ponto culminante dos ritos semanais no culto a Kali consiste, precisamente, na invocação de deuses e deusas nos corpos de certos especialistas religiosos, marlos. Marlos são homens e mulheres cujos corpos servem de veículos das revelações e dos tratamentos terapêuticos conduzidos pelas divindades. As manifestações de deuses e deusas não são homogêneas, pois sempre se realizam em determinados níveis: mais ou menos plenas, profundas ou puras. Em realidade, o shakti (poder) das deotas nunca se propaga por completo, pois os corpos dos humanos são capazes de suportar [sustain ou stand] apenas uma pequena parcela desse poder. Mas há gradações: alguém impuro é incapaz de suportar uma manifestação e somente através de treinamento é possível desenvolvê-la.

$O$ fator tempo é fundamental aqui. Manifestações se desenvolvem ao longo das semanas, a depender da constância da devoção e da observância de certas

8 O deslocamento de trabalhadores indianos para o Caribe fez parte de uma ampla dispersão global de trabalhadores da Índia no século XIX. No caso da Guiana, quase 240.000 trabalhadores e trabalhadoras da Índia imigraram para o local entre 1838 e 1917, data na qual o sistema de trabalho contratado [indentured labour] foi proibido pelo governo indiano. Para mais detalhes, consultar, dentre outros: Bahadur (2014), Laurence (1994), Look Lai (1993), Smith (1959) e Tinker (1993). 
prescrições. Não há iniciação propriamente dita, como em muitas formações religiosas afro-americanas. Normalmente, a presença continuada em templos, a oferta de alimentos e, eventualmente, animais, aos deuses e às deusas, e a constância das preces tornam as pessoas permeáveis (cf. Busby, 1997; Marriott, 1976; Nabokov, 2000) à manifestação divina. O treinamento está sob controle dos sacerdotes, mas em última instância é determinado pelas próprias divindades. Desse modo, e semelhantemente ao caso descrito por Ishii (2013), as divindades não existem apenas como protótipos cujos atos servem de modelo à incorporação, mas também constituem a origem do poder emanado em humanos.

Assim, duas condições são indispensáveis para a manifestação. Em primeiro lugar, constância da devoção - ir ao templo, rezar, fazer ofertas, focar os pensamentos nas atividades rituais. Em segundo lugar, manter-se puro ao entrar em contato com as divindades, artefatos rituais e altares. É indispensável observar rigorosamente a abstinência [fasting], evitando, três dias antes de ir ao templo, relações sexuais, a ingestão de alimentos de origem animal e o consumo de entorpecentes e bebidas alcoólicas. Mulheres menstruadas não podem acompanhar os ritos, tampouco quem tiver contato com pessoas recém-nascidas ou recém-falecidas. Em seu dia a dia, e em ocasiões específicas, humanos mantêm contato com pessoas, substâncias e seres impuros, daí ser necessário seguir certas prescrições, indispensáveis para manifestar mais plenamente e manter-se imune a afetações decorrentes da impureza.

Em Blairmont se diz tanto que as divindades se manifestam em humanos quanto que humanos manifestam divindades. ${ }^{9}$ A mesma divindade pode se manifestar em vários indivíduos simultaneamente, distribuindo-se parcial e diferencialmente em cada um deles. Divindades interagem entre si, dirigindo-se verbalmente umas às outras. Uma divindade refere-se a marlos em terceira pessoa e a si mesma em primeira pessoa, o que não anula a possibilidade de uma deota falar de si mesmo como se se referisse a outrem. Por exemplo, a deusa Kateri costuma dizer: "minha irmã [a deusa Mariamma] irá resolver isso";

9 Exemplos: "[a deusa] Kateri se manifesta em Arjune"; "Shakeran manifesta Kateri”. Em orações em primeira pessoa se diz: "Kateri se manifesta em mim." Além de manifestation, outros termos utilizados, com menor frequência, são: play, vibration e tek [take] the body - este último normalmente empregado em referência à ação de espíritos. 
"minha filha que faz meu marlo é muito devota"; "eu sou muito poderosa", e assim sucessivamente. A alternação entre primeira e terceira pessoa nas falas das deotas sucede porque idealmente pessoas que as manifestam não retêm lembrança alguma, pois a presença divina anula os sentidos, as sensações e a consciência das pessoas, acarretando em uma espécie de apagão, se diz. ${ }^{10}$

A anulação da consciência individual pelo poder divino não é tão transparente, contudo. Dadas as próprias limitações dos humanos, a manifestação das divindades enfraquece progressivamente, de modo que os sentidos normais do(a) marlo podem ser despertados paulatinamente, durante a manifestação. Não à toa, sacerdotes permanecem atentos aos sinais de enfraquecimento, refletido, por exemplo, na diminuição acentuada no ritmo da dança dos deuses. Nessas ocasiões utiliza-se de um expediente: o som de tamborins rituais é intensificado para dar maior plenitude à manifestação. Ou então as próprias divindades fazem uso dessa técnica, pois elas têm acesso ao estado interno de seus veículos humanos. Como notou Alfred Gell (1980, p. 237) em estudo realizado na Índia, se humanos se utilizam de técnicas corporais para ter acesso ao universo divino, as próprias divindades também necessitam dessas técnicas para realizar a si mesmas - daí que a manifestação pode decorrer também por conta de alguma dívida para com as divindades e/ou da insatisfação destas para com algum devoto.

Invariavelmente, as pessoas apresentam sinais de que uma divindade está prestes a se manifestar nelas: balançam suavemente suas cabeças, fecham os olhos, torcem os lábios, contraem as faces, têm espasmos, mas nem sempre começam a dançar. Os sinais emitidos pelas próprias divindades não impedem que as pessoas estimulem, por assim dizer, a manifestação nelas mesmas, afinal é necessário manter-se focado nas divindades, direcionando os pensamentos para elas. Lienhardt (1961, p. 62-65) já havia chamado a atenção para a existência de diversos contextos nos quais a possessão é esperada ou mesmo desejada. Como notou o autor, em certas circunstâncias, como os sacrifícios rituais, algumas reações são esperadas, exageradas e buscadas pelas pessoas, 0

10 Alguns dos informantes de Bassier (1977, p. 11), ao contrário, afirmaram estar semiconscientes, ou totalmente conscientes, do que ocorria, mas sem poder controlar seu corpo e seus pensamentos. 
que não invalida o fato de a possessão proceder de outras fontes e forças transcendentes à pessoa consciente que coopera com o porvir da possessão.

Como notou Scott (1994, p. 52-53, tradução minha), "os corpos são disciplinados, exercitados e treinados em função daquilo que pode ser vivido: capacidades, potencialidades e vulnerabilidades". Essas capacidades e vulnerabilidades não são simbolicamente transparentes, pois são constituídas por contatos e relações que tornam corpos permeáveis a distintas forças, energias e potências de seres que, por terem estatuto ontológico distinto, predicam efeitos distintos. É importante reter que mesmo marlos experientes podem alternar estados de inconsciência e semiconsciência, às vezes em uma mesma sessão ritual. Pode bem ser que algum(a) marlo manifeste plenamente as divindades de início, logo após a invocação. Porém, seu corpo eventualmente não sustenta a manifestação por longos períodos, de modo que a consciência pessoal passa a interferir mais e mais nos julgamentos expressos durante a manifestação. Existe a possibilidade de as deotas deixarem os corpos dos "médiuns" durante os rituais sem que a audiência perceba. As mensagens transmitidas nessas sessões são tomadas como índices fundamentais de inferência da profundidade das manifestações.

Em outras ocasiões, juízos mais enfáticos são proferidos, como nos constantes rumores sobre táticas empregadas em templos rivais. Inúmeras vezes ouvi relatos com o seguinte teor: pessoas de confiança de sacerdotes posicionam-se despretensiosamente ao lado de indivíduos que vão aos templos pela primeira vez para escutar seus diálogos, ou então entabulam conversas despretensiosas. Ao descobrirem os problemas pessoais desses indivíduos, os motivos que os levaram a procurar um templo de Kali, reportam esse conteúdo a sacerdotes e/ou médiuns. Assim, aquilo que aparenta ser uma revelação divina durante o tratamento nada mais é do que a transmissão de algo previamente conhecido por quem faz o marlo. Devotos mais experimentados recomendam a noviços, inclusive, que evitem a todo custo compartilhar seus problemas, em especial quando vão a um templo desconhecido. Esse é um modo efetivo de testar a veracidade das manifestações. ${ }^{11}$

11 No templo de Blairmont não era nada incomum ver cenas nas quais membros do local recusavam-se, terminantemente e com gestos expansivos, a ouvir qualquer comentário sobre a vida pessoal de alguém. Nah tell me not'in. Mother gon' fin' out [não me fale nada. A Deusa irá descobrir], dizia-se com frequência. 
Além dessas técnicas de engano, admite-se francamente a possibilidade de alguém forjar [fake] uma manifestação. Não é à toa, portanto, que as manifestações procedam, elas próprias, a verificações [proof]. Ou seja, quando irrompem no corpo de marlos, as divindades inserem cubos de vela acesos, ou mesmo erguem os braços para receber chibatadas, com cordas grossas e molhadas, em diversas partes do corpo. A razão para esses atos explica-se pelo seguinte motivo: um indivíduo comum, em seu estado normal, não passaria incólume a queimaduras e/ou golpes violentos de cordas. Somente divindades aguentariam [stand] isso, sem deixar marcas em seus receptáculos. ${ }^{12}$ Manifestações divinas não rebentam apenas com a invocação. Como algumas pessoas manifestam em outros momentos do rito semanal - e às vezes há um número grande delas nessa condição -, nem sempre é possível realizar as comprovações em todos aqueles que manifestam. É principalmente nessas circunstâncias que certos indivíduos fingem que manifestam

Em Blairmont, e em outros templos nos quais acompanhei sessões rituais, as verificações precedem a invocação, momento no qual se iniciam os tratamentos terapêuticos e as sessões oraculares. A expressão verbal dos pontos de vista das deotas é um dos últimos estágios do desenvolvimento da manifestação, pois a maneira pela qual as divindades se comunicam é, como dito, índice de sua plenitude. Quanto mais fluente e espontânea a fala de um(a) marlo, mais plena é sua manifestação. ${ }^{13}$ Talvez não seja coincidência o fato de a ingestão de cubos de velas acesas ser chamada de fire oath. É como se os próprios deuses fizessem um voto da autenticidade de suas presenças.

Em síntese, a manifestação é resultante da conjunção entre a devoção das pessoas, que deve ser contínua e tão irrestrita quanto possível, e a concessão de dádivas pelas divindades, que transferem partes ou essências de si mesmas (seus poderes, capacidades, pontos de vista) entre os humanos. Com os dados apresentados acima busquei demonstrar que técnicas particulares de discernimento de

12 Com efeito, já presenciei situações nas quais indivíduos receberam mais de 20 chibatadas em cada braço enquanto manifestavam divindades, sem que nenhuma marca desses golpes se mostrasse visível ao término dos ritos.

$13 \mathrm{O}$ fato de as divindades se comunicarem em inglês, e não em tâmil, como sucede em alguns templos, é valorizado em Blairmont. Para meus interlocutores, o diminuto número de indo-guianenses fluentes na língua dravidiana torna imperioso a presença de intérpretes, o que aumenta as possibilidades de fraude. 
presença de entes espirituais em contexto ritual são atravessadas pelo ceticismo, por incertezas, suspeições e desconfianças. Disso não decorre que se coloque em dúvida o poder das divindades, afinal de contas é indispensável ter fé para tornar-se permeável às dádivas divinas (Bassier, 1977; Kloß, 2016; McNeal, 2011; Mello, 2014; Singh, 1978; Stephanides; Singh, 2000). Em todo o caso, a desconfiança não é o reverso oposto da confiança (Carey, 2017; Mühlfried, 2018). Cabe, portanto, tomar essas noções de modo relacional, atentando para o modo pelo qual as pessoas emitem juízos em situações práticas específicas. Nas próximas páginas me deterei de forma mais detalhada sobre um caso em particular, no qual a presença de espíritos de colonizadores, em interação com divindades e devotos de Kali, complexifica nosso entendimento sobre aquilo que Michael Taussig (1993) chamou de faculdade mimética, isto é, a faculdade de copiar, imitar, explorar diferenças, tornar-se outro. Relações com a alteridade e a representação do outro ganham contornos específicos pragmaticamente.

\section{Deuses/espíritos}

José, um homem de meia idade, era dono de um bar, pai de três filhos e casado há vários anos. O bar, localizado no mesmo terreno de sua casa, era frequentado por várias pessoas, que se apraziam com a expansividade do proprietário, sempre disposto a juntar-se aos clientes para confraternizar. Paulatinamente, José passou a consumir cada vez mais bebidas alcoólicas durante e após seu expediente de trabalho. Desde então, seu estado físico e emocional se deteriorou, com uma perda excessiva de peso e alteração drástica de humor: o homem brincalhão e amoroso tornou-se agressivo com a família, que o levou, sob seus protestos, a Blairmont.

Alguns membros e frequentadores de Blairmont relacionaram a mudança de humor de José a três fatores: 1) o descaso de José para com as divindades; 2) a ligação dele e de sua família com outro templo de Kali, onde coisas más eram feitas; 3 ) a ação de vizinhos invejosos, que teriam recorrido a um feiticeiro para arruiná-lo. Enquanto certas pessoas sugeriram que algum espírito impelia o consumo excessivo de álcool, outros creditavam essa insaciabilidade a Khal Bhairo, deus que ingere bebidas alcoólicas nos rituais. Isto é, sugeriam algumas pessoas, o descaso de José com Khal Bhairo fez com que o próprio deus se hospedasse em José [host on him], fazendo-o beber. 
De qualquer forma, à parte essas especulações, poucos eram taxativos a respeito do que realmente se passava.

Em um domingo José foi a Blairmont para ser atendido por Khal Bhairo, que, naquela ocasião, se manifestava em Robert, um de seus filhos. Estava por perto nesse dia e acompanhei o seguinte diálogo. ${ }^{14}$

Khal Bhairo [manifestado no filho de José]: Onde está minha guirlanda [oferta de flores ao apreço das divindades]?

José: Desculpe, senhor [master]. Eu tive alguns problemas. Não consegui fazê-la. Khal Bhairo: Eu não estou aqui para brincadeiras, pujarie [termo de tratamento honorífico]. Eu sou o senhor [master] e eu sou o pai [father].

Khal Bhairo proferiu essas palavras com furor e tocou o ombro de José com uma cana brava, ameaçando espancá-lo. Em seguida, disse, irritado: "Onde estão meus cigarros?" "Onde está minha bebida?" Um assistente adentrou no templo do deus e pegou uma garrafa de rum disposta no altar, servindo uma dose, enquanto José retirou um maço de cigarros de seu bolso. Ao beber o rum, e entre uma baforada e outra dos três cigarros que fumava ao mesmo tempo, Khal Bhairo voltou a falar, dessa vez com um tom mais ameno:

Khal Bhairo: Pujarie, você deve vir preparado. Você não trouxe nada para me dar. A única coisa que eu peço é minha puja [oferta]. Você me deu seus cigarros. Está evidente que você está me dando isso por me dar, sem devoção e sem vontade verdadeira. Eu não estou em seus pensamentos. Você só bebe e bebe. Você está atormentando sua própria família. Ademais, seu vizinho plantou coisas em seu jardim. Você deve deixar de ir ao outro templo que frequenta. O pujarie [sacerdote, no caso] daquele local apenas quer fazer dinheiro às custas de suas desgraças [...] Enfim, você tem um problema na sua fronteira, ${ }_{15}^{15}$ pujarie. Você precisa

14 Muito raramente utilizei de gravadores em minhas pesquisas. Como eu estava diretamente envolvido nos rituais, me servi de um telefone celular para fazer anotações.

15 Boundary, embora indique limites, não equivale exatamente aos marcos que definem, separam e conectam dois espaços (a fronteira de uma casa não equivale, por exemplo, a um espaço confinado por cercas, nem corresponde ao limite de dois terrenos). Nesse contexto, boundary refere-se tanto ao terreno onde se erigiu a casa de uma família quanto a seus arredores. Yard work é um trabalho que envolve a preparação de uma mesa para um espírito holandês. Ver abaixo. 
fazer um yard work [trabalho realizado para espíritos holandeses em âmbito doméstico]. Faça os arranjos com meu sacerdote [o sacerdote de Blairmont, Bayo, no caso].

José escutou tudo passivamente, desorientado. Repentinamente, uma nova presença se materializou, alterando a percepção e o estado emocional do par que interagia. Vejamos:

Khal Bhairo: [berrando] Quem está dentro do meu filho [child]? Fale comigo! Seja o que for que está aí, fale comigo agora! Fale! Eu exijo!

José permaneceu postado no mesmo lugar, atônito, balançando lentamente o corpo de um lado a outro. Khal Bhairo voltou à carga:

Khal Bhairo: Eu sou o pai e o senhor. Você pode correr, mas não se esconder. Eu vou pegá-lo porque eu sou o pai. Eu comando e controlo tudo. Ninguém pode comigo. Eu sou o senhor. Mostre-se. Mostre-se, agora! Eu sei que você está aí.

Subitamente, José começou a pular e a dançar com os olhos fechados, com um braço esticado acima da cabeça e com expressões de dor em seu rosto, balançando o rosto de um lado a outro. A divindade à sua frente pegou um ramo de folhas neem, instrumento de cura, e passou a golpeá-lo violentamente, gritando:

Khal Bhairo: Você quer se passar por mim, hein? Você acha que pode me enganar? Eu sei que você está aí. Quem é você? Diga seu nome! Diga, se tem coragem. Eu sou terrível. Você não vai escapar.

Diante da mudez e da impassibilidade de José, Khal Bhairo dirigiu-se aos presentes, repetindo que era o senhor, o pai e que ninguém poderia escapar dele, nem mesmo aquela coisa, certamente a mesma responsável por criar problemas para seu filho. Paulatinamente, José recobrou os sentidos, sendo alimentado, banhado, varrido e aconselhado pela divindade. Sua esposa, sempre por perto, logo se encarregou de procurar o sacerdote para fazer os arranjos do yard work. Khal Bhairo, por sua vez, continuou a atender outros devotos utilizando-se do corpo de Robert como veículo de cura. 
O entendimento desse tipo de episódio nunca é imediatamente evidente. É por meio de uma sucessão de camadas de interpretações, debates, discussões e olhares retrospectivos acerca de pequenos acontecimentos que vereditos (cf. Pelkmans, 2013) se formulam e se consolidam entre as pessoas. Quando acompanhei a interação narrada acima, pude discernir o que se passava porque já havia presenciado outras situações nas quais espíritos e outros seres malignos se manifestaram no templo. No caso em pauta, entende-se a explosão de fúria de Khal Bhairo ao levar-se em conta três fatores: 1) o fato de José ter sido possuído por um espírito; 2) por esse espírito ser o causador de problemas àquele e à sua família; 3) pelo espírito ter se passado por uma divindade.

Pequenos sinais podem confundir o observador e aqueles envolvidos com a situação. Quando alguém manifesta Khal Bhairo, a gestualidade é um dos índices da presença dessa divindade (e não de outra): é que Khal Bhairo costuma dançar pulando em uma perna só, ou então levantando seu braço acima da cabeça. O corpo de José moveu-se exatamente assim, mas esse índice corporal mascarou outra presença: o espírito, por meio de José, engajou-se em uma relação mimética com o deus em questão. Foram justamente as falas de Khal Bhairo, seus desafios e sua denúncia de que alguém se passava por ele que definiram quem estava se manifestando em José. A enunciação é um momento-chave da relação.

Gostaria de abordar outras problemáticas a partir de uma zombaria feita por um jovem assistente de Blairmont, Ryan, ao comentar esse ocorrido. Disse o rapaz: "Pobre José. Apanhou do filho e ainda teve que ouvi-lo dizer que ele era o pai." Especificamente, Ryan se referia à cena do espancamento e aos pronomes usados pela manifestação de Khal Bhairo [my child e I'm the father]. Esse comentário, tão irônico quanto sugestivo, associa-se à possibilidade já apontada de alguém fingir que está manifestando, ou então ter feixes de consciência. O que ocorre quando um marlo (Robert, nesse caso), cuja consciência individual idealmente é anulada pelo shakti, é diretamente envolvido com quem busca ajuda? Afinal, quem manifestava Khal Bhairo nessa ocasião era o filho de José. Robert interagiu com José na condição de Khal Bhairo, mas é impossível saber, em última instância, se os modos de relacionalidade entre parentes interferiram na relação entre Robert/Khal Bhairo e José.

Nesse caso, a chacota de Ryan não era uma acusação quanto à plenitude da manifestação de Robert - ou melhor, pode-se dizer que retrospectivamente esse comentário não se tornou uma acusação. As manifestações de Robert, 
por sinal, sempre foram consideradas profundas, dada a força do shakti em seu corpo, sua capacidade de sustentá-lo por horas a fio e dos feitos de Khal Bhairo em Robert. O comportamento da manifestação de Robert na interação com José, ademais, condizia com a maneira pela qual Khal Bhairo se apresenta aos devotos. Esse deus, simultaneamente bom e terrível, em suas próprias palavras, dirige-se às pessoas chamando-as de my child, se proclama o pai e o senhor, 0 que reverbera alguns dos temas mitológicos a ele associados (ver Mello, 2014). Ao desmascarar outra presença no corpo de José, Khal Bhairo assegurou ser capaz de controlá-la, desde que o fluxo de interação não fosse interrompido. Para tanto, cabia a José e à sua família averiguar o que tal ente desejava. Passadas algumas semanas, uma nova etapa do tratamento teve lugar, dessa vez na casa de José, onde a presença do espírito foi convocada em outros termos. Se a conduta de Khal Bhairo, no corpo de Robert, foi tomada como índice de autenticidade da manifestação desse deus, algumas dúvidas ainda pairavam no ar.

\section{O senhor da terra}

Na interação entre Khal Bhairo e José, o deus desmascarou outra presença e alertou-o sobre o problema em sua casa. Soube-se, posteriormente, através de novas revelações de Khal Bhairo - feitas por meio de outra marlo, Sundar - e da recapitulação de fatos passados (ver abaixo), que um espírito holandês era o dono da terra onde viviam José e sua família. Em um dia de semana, Bayo, sacerdote de Blairmont, auxiliado por um sacerdote assistente, um sacrificador, por mim e por outro marlo, Rickie, fomos à casa de José para realizar um trabalho e descobrir exatamente o que o espírito desejava - afinal, como já mencionado anteriormente, as reais intenções desses seres são frequentemente ambíguas, devido ao seu caráter traiçoeiro. Passo agora à descrição do que ocorreu nessa ocasião.

Quando os membros do templo chegaram à casa, por volta das sete horas da noite, todos se reuniram na cozinha e sentaram-se no chão, ou em cadeiras, em volta de uma mesa, ${ }^{16}$ na qual estavam dispostos vários itens: frutas (abacate, banana, mamão e maçã), uma galinha assada, pão com queijo, macarrão

16 Daí o yard work ser conhecido, também, como table work. 
[chow mein], ketchup e pimenta, perfume, quatro copos plásticos preenchidos com arroz (em três deles, colocou-se uma vela branca no centro), balas, bolos, biscoitos de chocolate, água mineral, garrafas de refrigerantes, café, e garrafas de vodca e rum. Rickie, um jovem que incorporava as deusas Kateri e Mariamma em Blairmont, sentou-se em frente à mesa, cruzou as pernas e juntou as palmas das mãos, sussurrando algo inaudível. Permaneceu imóvel por alguns segundos e, subitamente, seu corpo foi projetado para trás, como se algo tivesse o golpeado. Respirou fundo, abriu os olhos, dos quais só se podia avistar a esclerótica e, a partir de então, não era mais Rickie quem estava ali: o holandês tomou seu corpo. ${ }^{17}$

Saudando a todos jovialmente, com um forte sotaque, ${ }^{18} \mathrm{o}$ espírito desejou boa noite. Bayo, o sacerdote, postado à sua esquerda, em uma cadeira, retribuiu a saudação e agradeceu sua presença, dando início a um diálogo:

Bayo: Baba [termo de tratamento honorífico entre indo-guianenses], você deve saber a razão pela qual o chamamos hoje. Essa família tem sofrido muito com as ações de José, mas ele quer melhorar e pedir sua ajuda. Nós lhe pedimos que nos auxilie, por favor.

Holandês: Eu também quero resolver essa situação. Estou ouvindo vocês.

Bayo: Nós temos algumas suspeitas, mas queríamos saber se o lugar está contaminado.

Holandês: Sim [ya].

Bayo: Nós sabemos que há muitos senhores [masters, espíritos no caso] neste lote de terra. Eles podem estar com inveja.

O holandês interrompeu o diálogo e perguntou se, por gentileza, poderia beber um pouco de vodca e fumar cigarros. José lhe serviu a bebida e lhe alcançou um maço de cigarros. Enquanto esteve presente em Rickie, por aproximadamente

17 O modo pelo qual as pessoas invocam espíritos holandeses em seus corpos é algo um tanto misterioso, pois é necessário se estabelecer relações continuadas com espíritos para invocá-los, por meio de fórmulas secretas.

18 Por várias vezes, o holandês disse que não sabia qual era a palavra exata que deveria usar, pedindo ajuda aos presentes. Seu sotaque era tão acentuado que em alguns momentos os membros do templo e a família de José lhe pediram para repetir as frases. Não gravei nem tomei nenhuma nota durante essa conversação. Tão logo cheguei ao local onde estava hospedado, duras horas depois de o serviço ter acabado, reorganizei palavras-chave anotadas no celular e complementei a descrição com o que ainda me lembrava. 
uma hora, o espírito entornou metade da garrafa de vodca e fumou por volta de quinze cigarros. $O$ consumo de alguns dos itens da mesa sempre foi intermediado por pedidos de licença e por saudações. A galinha, temperada fartamente com ketchup e com pimenta, foi degustada vagarosamente, sendo apreciada entre doses de bebida e cigarros. Após tomar a primeira dose, o holandês chamou José:

Holandês: Você sabe qual é o problema, não?

José: Eu imagino. Tenho bebido muito.

Holandês: Não é isso. O que você faz quando bebe?

Entrementes, a esposa de José, Sati, tomou parte no assunto, impedindo qualquer reação do marido:

Sati: Ele não para de beber. Eu não consigo dormir. Eu tenho que chavear a porta do bar, senão ele tenta roubar a bebida. Todo dia é isso. Todo dia! Holandês: [dirigindo-se a José] Viu o que você está causando?

À parte essa intervenção, Sati não interferiu no rumo das conversações, pelo menos não enfaticamente. Em praticamente toda a "consulta", ela permaneceu resmungando, em voz baixa, os transtornos causados pelo marido, queixando-se de cansaço. A palavra voltou ao espírito:

Holandês: Responda-me. O que você faz quando bebe?

José: Eu não lembro.

Holandês: Eu vou lhe dizer. Você vai para o quintal no meio da noite, e fica despejando rum e cerveja no chão, oferecendo-os a todos [outros espíritos, no caso], menos para mim. Não fale e não fale dos outros. Quais nomes você fala? José: Eu não sei exatamente.

Holandês: Exato. Você chama a todos, mas não me dá nada. E eu sou o dono dessa fronteira. $\mathrm{O}$ que você me deu, hein?

Nesse momento, Bayo deu um suspiro, olhou para todos, balançou a cabeça, e dirigiu-se a José: "Nós te avisamos." Voltando-se para o espírito holandês, continuou a dar sua opinião, dizendo que um dos motivos de sua presença ali era para resolver a situação. “Vocês têm algo para mim?”, perguntou o espírito. 
Um galo, de cor branca, foi trazido do fundo do quintal, e o visitante passou a segurá-lo em seu colo, alisando-o e lhe fazendo carinho, como se intentasse acalmá-lo. Trazendo-o para mais perto de si, o holandês serviu vodca em um copo e deu de beber ao galo.

Nesse ínterim, voltou à carga, confirmando a suspeita geral: José estava bebendo muito porque ele próprio o fazia beber; ele precisava de algo, mas não era recompensado [rewarded]. Em seguida, disse algo como: "Se você tivesse me dado alguma coisa desde o início, nada disso teria acontecido. Seu vizinho também é um problema, assim como o sacerdote do templo que vocês frequentavam", completou. Ao ouvir isso, Bayo novamente se movimentou na cadeira, quase extasiado por confirmar novamente suas suspeitas, enquanto Sati murmurou: "Eu achei um sapo [crapo] no quintal. Esses vizinhos ficam jogando tudo quanto é coisa aqui dentro."

Antes mesmo de o trabalho ser agendado, os membros de Blairmont (e Khal Bhairo) já haviam apontado as ações do vizinho e do sacerdote do templo outrora frequentado por José e por sua família como uma das causas de seu sofrimento. Em verdade, as duas coisas estavam conjugadas. Os vizinhos tinham muita inveja e ao buscarem ajuda em outro templo, a família incorrera em erro grave: o próprio sacerdote dali estava mancomunado com tal vizinho, além de ter os aconselhado, imprudente e malevolamente, a fazer uma mesa daquelas todos os meses, o que nunca deveria ter sido levado a cabo, pois não se deve atiçar a cobiça de um holandês.

Ademais, tal mesa era ofertada aos espíritos errados, não ao dono da terra. Os membros de Blairmont souberam disso através das reclamações de Sati, cujas suspeitas em relação ao sacerdote do outro templo aumentaram depois de perceber que a vida de todos não progredia. Pelo contrário, desgraças recaíram sobre a família a partir do momento em que passaram a ir àquele local. Depois de ouvir a tudo pacientemente, enquanto fumava, bebia e comia, o espírito deu outro conselho a José: "Pare de ir àquele templo. Continue no templo do sacerdote que está aqui hoje." Fez uma pausa, e perguntou: "Você quer falar alguma coisa?"

José inquietou-se, sentou em frente ao master e pediu licença para fumar também - gesto que fez alguns dos presentes sorrirem ironicamente. Entre uma baforada e outra, José confirmou que se sentia melhor desde o dia em que foi a Blairmont, quando se tratou com Khal Bhairo. Pediu perdão a todos e ponderou que era muito difícil parar de beber. "Esforce-se mais", interrompeu o holandês. 
A conversa prosseguia a fio e parecia longe do desfecho. Passados mais alguns minutos, o espírito entregou o galo de volta, indicando, com um aceno, que aceitava a oferenda. José, acompanhado do sacrificador de Blairmont, foi até o quintal, cavou um buraco perto de uma árvore e segurou o animal enquanto aquele consumava o sacrifício. A cabeça foi arrancada, colocada no chão por um instante e um cigarro foi aceso no bico do galo, no qual se despejou vodca, enquanto o sangue escorria lentamente no buraco, onde a cabeça foi enterrada. Bayo aproveitou o ensejo e disse:

Bayo: Bom, Baba, já é tarde e nós moramos longe. Queríamos saber se você está satisfeito.

Holandês: Ya.

Bayo: $\mathrm{E}$ quanto aos demais senhores [masters]?

Holandês: Não se preocupe. Eu sou o verdadeiro senhor [master]. Eu controlo a fronteira e todos que estão aqui. Ninguém mais vai perturbá-los. Apenas me deem o que é do meu direito.

O espírito passou a conversar privadamente com a filha de José, uma menina de apenas oito anos de idade, enquanto os demais presentes se dirigiram a um aposento anexo. Não soube qual foi o teor exato do diálogo com a menina, mas devo notar que os outros dois filhos de José e de Sita, Robert incluso, quedaram-se mudos durante todo o trabalho. Depois de aproximadamente dez minutos, o espírito chamou a todos novamente, agradeceu-lhes a presença e fez um último alerta a José: "Pense na sua filha, homem. Se você quer alguma coisa, sacrifique-se."

Em seguida, o corpo de Rickie tremeu-se todo, projetando-o no chão. O espírito partira. Um limão foi espremido em volta de Rickie para afastar possíveis contaminações, José ofereceu-nos comida e cerveja e partimos de volta para nossos locais de moradia. Semanas depois, José reapareceu em Blairmont, com muitos quilos a mais, repleto de sorrisos e manifestando gratidão aos membros do templo e às divindades, em especial a Khal Bhairo. Seu problema fora resolvido. ${ }^{19}$

19 Esses acontecimentos se deram em 2011. Anos depois, em 2018, soube que toda a família migrou para o Canadá, outro sinal evidente de prosperidade. 


\section{Mimesis, dúvida e poder}

Em um instigante texto sobre indeterminação e corporalidade mimética em Porto Rico, Raquel Romberg (2014) pergunta-se de que modo dúvidas sobre a veracidade de eventos de possessão espiritual são formuladas sem, necessariamente, negar-se totalmente a autenticidade das mensagens transmitidas por entes espirituais. Ao se tratar de percepções coletivas e julgamentos individuais é fundamental, sugere a autora, perguntar-se quem está sendo testado: médiuns? Entes espirituais? Ou ambos? Wirtz (2007), por sua vez, demonstra que atitudes céticas são integrais às manifestações de fé de santeros em Santiago de Cuba, concorrendo para a avaliação de performances rituais por meio de expectativas e olhares retrospectivos. A avaliação da autenticidade de experiências religiosas é variável: diferentes participantes dos rituais reportam diferentes interpretações de eventos religiosos. Com efeito, como sugeriram Lambek (1981) e Boddy (1989) de forma pioneira, a possessão espiritual tem o potencial de estabelecer canais de comunicação por meio dos quais mensagens transmitidas por espíritos podem alterar significativamente as interpretações de eventos passados, do presente e do porvir, justamente por terem conotações subversivas, ainda que ambivalentes e ambíguas, como notou Boddy (1989) para o caso de mulheres que interagem com os zar no Sudão. Cumpre destacar, justamente, que a autoridade e a veracidade implícitas nas mensagens transmitidas por entes espirituais não são transparentes.

Em um interessante texto, Judith Irvine (1982) pergunta-se de que modo pessoas que testemunham episódios de possessão espiritual interpretam-nos como instâncias de mediunidade. Para a autora, cabe analisar como atos verbais e outros meios comunicativos concorrem para a consolidação, ou não, de certas interpretações, bem como para a definição dos significados desses eventos em contextos específicos. Assim, a inteligibilidade da comunicação espiritual não é propriedade dos códigos de espíritos em si mesmos, mas um "tema negociável envolvendo a participação de membros da audiência" (Irvine, 1982, p. 244, tradução minha). Diferentes ocasiões rituais, por sua vez, ainda que possam clarificar os significados de certos comportamentos - tome-se como ilustração as reações do sacerdote de Blairmont após a confirmação de suas suspeitas pelas explanações do espírito - não necessariamente encerram controvérsias e dúvidas; ao contrário, rituais podem fornecer mais elementos para deliberação. 
Esses apontamentos são relevantes para se pensar o próprio modo como construí minha narrativa sobre o caso de José. Uma série de rituais e interações entre distintos agentes resultou no efeito desejado - a cura de José, inclusive por meio de ofertas dedicadas ao espírito. As incertezas causadas pela própria aparição do espírito progressivamente deram lugar à consolidação de interpretações sobre o que estava ocorrendo e sobre o que deveria ser feito. A intervenção do deus Khal Bhairo, desmascarando uma presença que ocultava a real identidade do espírito, sessões oraculares e o diálogo durante o table work não configuraram uma sequência linear de eventos, cujos significados já estavam dados. Certas suspeitas foram efetivamente confirmadas, mas poderiam não o ser: os rumos das interações, e a consolidação de certos vereditos e de certas interpretações, ganharam forma paulatinamente. Nesse sentido, minha narrativa, embora enquadre certos eventos em uma sequência temporal, busca destacar o caráter mutável de históricas marcadas pela presença de espíritos (ver Cardoso, 2007).

A partir do caso aqui reconstituído em maior detalhe, pode-se dizer que os pontos de vista veiculados por espíritos, divindades e devotos(as) de Kali, dentro e fora do templo de Blairmont, foram marcados por uma série de "validações empíricas" (cf. Pelkmans, 2013) de mensagens transmitidas em distintos momentos. O modo pelo qual tais validações se tornam vereditos (ou melhor, versões estabilizadas sobre certos acontecimentos e seus desdobramentos) é repleto de evidências fragmentárias, ambivalências, dúvidas, hesitações e testes de hipóteses. Assim, o "senso do inesperado" (cf. Cardoso, 2007, 2014) da agência de entes espirituais torna a dúvida um elemento central das interações entre espíritos, divindades e humanos. Dúvidas não necessitam ser abordadas à luz de suas funções sociais, nem enquanto aspectos transitórios de crenças (ver Holbraad, 2012; Bubandt, 2014). Como notou Pelkmans (2013), dúvidas e incertezas apontam não apenas para questões ontológicas (o que é) ou epistemológicas (o que é verdade), mas também para referentes pragmáticos, para a questão do que fazer.

Os problemas de José desestabilizaram seu meio doméstico e culminaram na intrusão de um espírito no espaço ritual de Blairmont. Embora as divindades hindus possam curar as pessoas de influências malignas, o preceito estabelecido é o de que espíritos não devem ser cultuados no templo - somente em âmbito doméstico ofertas a espíritos podem ser levadas a cabo. Ainda assim, 
o espírito rebentou em Blairmont para dar mostras de suas demandas e de seu poder sobre José, mimetizando seres igualmente poderosos, as divindades hindus. Não obstante a denúncia imediata de Khal Bhairo, pode-se dizer que a busca pela semelhança pode consistir em um meio, um estágio intermediário. Como notou Caillois (1984, p. 27) em um instigante texto, a assimilação ao espaço pode se dar pela despersonalização, pela incorporação de atributos distribuídos em uma ambiência e dos seres que nela habitam. A semelhança é obtida pela combinação de um certo número de pequenos detalhes que, isoladamente, não têm nada de excepcional, mas cuja combinação produz um resultado único.

De acordo com meus interlocutores, espíritos holandeses são artífices de trapaças, deleitam-se em trair as expectativas das pessoas com falsas promessas, ${ }^{20}$ se fazem passar por divindades, ou mesmo assumem compleições físicas distintas para atingir seus fins. ${ }^{21}$ De fato, fraudes, artifícios, ocultações e truques são técnicas potencialmente eficazes (Taussig, 2016, p. 463). Em alguma medida, José - e sua família - lograram benefícios após uma série de tormentos porque o espírito, autointitulado senhor da terra, foi nutrido com ofertas rituais, atestando sua soberania sobre um espaço habitado inclusive por outros espíritos.

O desfecho dessa relação, entretanto, não estava dado. Em primeiro lugar porque espíritos holandeses não são facilmente expelidos de seus lugares de habitação; no máximo, são aplacados. Em segundo lugar, e como já mencionado, são traiçoeiros e, tal como os colonizadores holandeses no passado, gananciosos. Por mais curioso que possa parecer, do ponto de vista de guianenses de todas as origens étnicas da região costeira do país os verdadeiros donos da terra não são os ameríndios, mas justamente os espíritos holandeses. Nesse

20 Descrevi em outro lugar (Mello, 2014, p. 367-406) outros casos de aflições causadas por espíritos holandeses, um dos quais teve desfecho particularmente dramático: uma jovem suicidou-se após os ataques recrudescerem, mesmo após a (falsa) promessa de um espírito, que afirmou, publicamente, que não causaria mais transtornos à jovem após receber ofertas rituais.

21 No caso de ataques sexuais em sonhos, espíritos holandeses podem assumir a forma de homens e/ou mulheres de distintas origens, assemelhando-se a pessoas de origem europeia, africana ou indiana, por exemplo. Por motivos de espaço não tratarei aqui dos sonhos, algo a ser trabalhado em outro artigo (ver, entretanto, Mello, 2014, p. 373-381). 
sentido, as imagens de autoctonia associadas a esses seres são uma fonte de onde estes retiram parte de seu poder.

No único artigo publicado que trata extensamente, e de forma criativa, de espíritos holandeses na Guiana, Brackette Williams (1990) acompanhou situações nas quais espíritos recontaram suas histórias e suas tragédias pessoais a moradores da região costeira do país. Segundo Williams, ao evocarem acontecimentos traumáticos do passado, marcados por atrocidades impetradas pelos britânicos, os espíritos esforçavam-se por ter suas histórias conhecidas, dirigindo sua vingança a guianenses no presente, que eram considerados, por aqueles, como os herdeiros das propriedades e do poder que perderam nas disputas com outros colonizadores. Homens e mulheres guianenses utilizavam-se de características das representações anglo-holandesas, e de estereótipos sobre grupos étnicos (cf. Williams, 1991), para formular o conteúdo e a estrutura dos rituais nos quais espíritos holandeses participavam, que informavam, por sua vez, as respostas humanas à presença continuada dos espíritos no país e em suas vidas. Assim, nas interfaces entre vivos e mortos, os espíritos incorporavam vários arquétipos coloniais, evocando autoctonia, violência, brutalidade e falsidade (Williams, 1990, p. 148-149). Na linha de argumentação aberta pela autora, sugeri, igualmente, que a aquisição e a transmissão de conhecimento histórico associado a imagens de violência do passado colonial passam necessariamente pelas relações entretidas com espíritos.

A incorporação, ainda que parcial e limitada, de espíritos em espaços rituais hindus aponta para o fato de que o universo espiritual do culto a Kali expandiu-se com a experiência histórica (ver Stoller, 1989, para uma análise mais detalhada desse tópico entre os Songhay). Para os fins deste artigo, interessa reter que imagens sobre o passado colonial, tal como encarnadas pelos espíritos holandeses, informam o próprio modo pelo qual poderes perigosos podem ser invocados, canalizados e transgredidos. Com efeito, a intervenção de divindades e de especialistas religiosos que mobilizaram inclusive o espírito que afligia José foi fundamental para o desfecho de seu tratamento terapêutico. É necessário destacar que alguns membros de Blairmont julgam temerário aconselhar-se com holandeses, devido à sua índole traiçoeira. Ademais, indivíduos que invocam espíritos holandeses em seus corpos (sempre homens, até onde pude apurar) devem ser extremamente cautelosos para não serem afetados e/ou incorporarem, em suas vidas, predicados dos espíritos, afinal a 
fusão de perspectivas pode ter efeitos indesejados e perigosos. Como notou Willerslev (2007) em outro contexto, a perspectiva e a identidade de sujeitos não necessariamente são atributos fixos ou estáveis, mas antes uma condição vulnerável passível de ser transformada, ou mesmo dissolvida, pela dinâmica das relações entretidas com entes espirituais. No caso do culto a Kali, é recomendável, aliás, que indivíduos que invocam espíritos holandeses sejam marlos, pois a presença de divindades hindus em seus corpos contrabalança efeitos nocivos. Manifestar divindades implica outra ordem de consubstancialidade: 0 shakti, poder divino, é dotado da capacidade de anular poderes nocivos.

As intersecções entre os pontos de vista de espíritos, divindades e humanos abriram espaço para potenciais imaginativos para aquilo que poderia, do contrário, não ser falado, ser inacessível, ou inatingível (cf. Wirtz, 2014). Em um cenário marcado por dúvidas, a intervenção prática em uma ordem de relações amparou-se em versões estabilizadas sobre as ordens de causação de pequenos acontecimentos. Os procedimentos rituais levados a cabo no templo e na residência de José decorreram, em larga medida, das revelações divinas, expressas em um cenário no qual a verdade é constantemente questionada pela própria veracidade dos seres (cf. Taussig, 2016) que expressaram seus pontos de vista. Para a sorte de José (e de sua família), a manifestação de Khal Bhairo foi plena, isenta de equívocos e enganos. Em um universo povoado por forças espirituais, os poderes de espíritos holandeses foram canalizados de modo positivo, mormente porque as tentativas de fraude do espírito não passaram pelos testes do poder divino.

\section{Referências}

BAHADUR, G. Coolie woman: the odyssey of indenture. Chicago: The University of Chicago Press, 2014.

BASSIER, D. W. Kali Mai worship in Guyana: an overview. Georgetown: University of Guyana, 1977.

BLANES, R.; ESPÍRITO SANTO, D. Introduction: on the agency of intangibles. In: BLANES, R.; ESPÍRITO SANTO, D. (ed.). The social life of spirits. Chicago: The University of Chicago Press, 2014. p. 1-31. 
BODDY, J. Wombs and alien spirits: women, men, and the Zar cult in Nothern Sudan. Madison: The University of Wisconsin Press, 1989.

BUBANDT, N. The empty seashell: witchacraft and doubt on an Indonesian island. Ithaca: Cornell University Press, 2014.

BUSBY, C. Permeable and partible persons: a comparative analysis of gender and body in South India and Melanesia. The Journal of the Royal Anthropological Institute, v. 3, n. 2, p. 261-278, 1997.

CAILLOIS, R. Mimicry and legendary psychasthenia. October, v. 31, p. 16-32, 1984.

CAIXETA DE QUEIROZ, R. Jean Rouch: o sonho mais forte que a morte. Devires, v. 1, n. 2, p. 110-147, 2004.

CARDOSO, V. Narrar o mundo: estórias do "povo da rua" e a narração do imprevisível. Mana, Rio de Janeiro, v. 13, n. 2, p. 317-345, 2007.

CARDOSO, V. Spirits and stories in the crossroads. In: BLANES, R.; ESPÍRITO SANTO, D. (ed.). The social life of spirits. Chicago: The University of Chicago Press, 2014. p. 93-107.

CAREY, M. Mistrust: an ethnographic theory. Chicago: Hau Books: The University of Chicago Press, 2017.

FREIRE, B. Táticas táteis ou um certo tato tático: o corpo extenso de Jean Rouch. R@u: Revista de Antropologia da UFSCAR, v. 2, n. 1, p. 47-72, 2010.

GELL, A. The gods at play: vertigo and possession in Muria religion. Man, v. 15, n. 2, p. 219-248, 1980.

GONÇALVES, M. A. O real imaginado: etnografia, cinema e surrealismo em Jean Rouch. Rio de Janeiro: Topbooks, 2008.

GONÇALVES, M. A. Encontros "encorporados" e reconhecimento pelo corpo: filme e etnografia em Jean Rouch. Devires, v. 6, n. 2, p. 28-45, 2009.

HOLBRAAD, M. Truth in motion: the recursive anthropology of Cuban divination. Chicago: The University of Chicago Press, 2012.

IRVINE, J. The creation of identity in spirit mediumship and possession. In: PARKIN, D. (ed.). Semantic anthropology. London: Academic Press, 1982. p. 241-260.

ISHII, M. Playing with perspectives: spirit possession, mimesis, and permeability among the buuta ritual in South India. The Journal of the Royal Anthropological Institute, v. 19, n. 4, p. 795-812, 2013. 
JOHNSON, P. C. An Atlantic genealogy of "spirit possession". Comparative Studies in Society and History, v. 53, n. 2, p. 393-425, 2011.

KEANE, W. The evidence of senses and the materiality of religion. The Journal of the Royal Anthropological Institute, v. 14, p. S110-S127, 2008.

KLOß, S. Fabrics of indianness: the exchange and consuption of clothing in transnational Guyanese Hindu communities. New York: Palgrave MacMillan, 2016.

KRAMER, F. The redfez: art and spirit possession in Africa. London: Verso, 1993.

LAMBEK, M. Human spirits: a cultural account of trance in Mayotte. Cambridge: Cambridge University Press, 1981.

LAURENCE, K. O. A question of labour: indentured immigration into Trinidad and British Guiana, 1875-1917. Kingston: Ian Randle, 1994.

LIENHARDT, G. Divinity and experience: the religion of the Dinka. Cambridge: Claredon, 1961.

LOOK LAI, W. Indentured labor, Caribbean sugar: Chinese and Indian migrants to the British West Indies, 1838-1918. Baltimore: John Hopkins University Press, 1993.

MARRIOTT, M. Hindu transactions: diversity without dualism. In: KAPFERER, B. (ed.). Transaction and meaning: directions in the anthropology of exchanging and symbolic behavior. Philadelphia: Institute for the Study of Human Issues, 1976. p. 109-142.

MCNEAL, K. Trance and modernity in the Southern Caribbean: African and Hindu popular religions in Trinidad and Tobago. Gainesville: University Press of Florida, 2011.

MELLO, M. M. Devoções manifestas: religião, pureza e cura em um templo hindu da deusa Kali (Berbice, Guiana). 2014. Tese (Doutorado em Antropologia Social) - Museu Nacional, Universidade Federal do Rio de Janeiro, Rio de Janeiro, 2014.

MELLO, M. M. Murtis em movimento: relações entre pessoas, coisas e divindades em um templo hindu na Guiana. Mana, Rio de Janeiro, v. 24, n. 1, p. 103-130, 2018.

MENTORE, G. Of vital spirits and precarious bodies in Amerindian socialities. In: FORDE, M.; HUME, Y. (ed.). Passages and afterworlds: anthropological perspectives on death in the Caribbean. Durham: Duke University Press, 2018. p. 54-79.

MÜHLFRIED, F. (ed). Mistrust: ethnographic approximations. Bielefeld: Transcript, 2018.

NABOKOV, I. Religion against the self: an ethnography of Tamil rituals. Oxford: Oxford University Press, 2000. 
PELKMANS, M. Outline for an ethnography of doubt. In: PELKMANS, M. (ed.). Ethnographies of doubt: faith and ucertainty in contemporary societies. London: Tauris, 2013, p. 1-42.

ROMBERG, R. Mimetic corporeality, discourse, and indeterminacy in spirit possession. In: JOHNSON, P. C. (ed.). Spirited things: the work of possession in Afro-Atlantic religions. Chicago: The University of Chicago Press, 2014. p. 225-256.

SCOTT, D. Formations of the ritual: colonial and anthropological discourses on the Sinhala Yaktovil. Minneapolis: University of Minnesota Press, 1994.

SEVERI, C. Cosmologia, crise e paradoxo: da imagem de homens e mulheres brancos na tradição xamânica Kuna. Mana, Rio de Janeiro, v. 6, n. 1, p. 121-155, 2000.

SINGH, K. Kali Mai puja: a study of a Guyanese East Indian folk cult in its social-cultural context. Georgetown: Department of Caribbean Studies, University of Guyana, 1978.

SMITH, R. Some social characteristics of Indian immigrants to British Guiana. Population Studies, v. 13, n. 1, p. 34-39, 1959.

STEPHANIDES, S.; SINGH, K. Translating Kali's feast: the goddess in Indo-Caribbean ritual and fiction. Amsterdam: Rodopi, 2000.

STOLLER, P. Fusion of the worlds: an ethnography of possession among the Songhay of Niger. Chicago: The University of Chicago Press, 1989.

STOLLER, P. The cinematic griot: the ethnography of Jean Rouch. Chicago: The University of Chicago Press, 1992.

STOLLER, P. Embodying colonial memories: spirit possession, power and the Hauka in West Africa. London: Routledge, 1995.

STOLLER, P. Sensuous scholarship. Philadelphia: University of Pennsylvania Press, 1997.

SZTUTMAN, R. Imagens perigosas: a possessão e a gênese do cinema de Jean Rouch. Cadernos de Campo, n. 13, p. 115-124, 2005.

SZTUTMAN, R. A antropologia reversa de Jean Rouch: de Os mestres loucos a Petit à petit. Devires, v. 6, n. 1, p. 108-125, 2009.

TAUSSIG, M. Shamanism, colonialism and the wild man: a study in terror and healing. Chicago: The University of Chicago Press, 1987.

TAUSSIG, M. Mimesis and alterity: a particular history of the senses. New York: Routledge, 1993. 
TAUSSIG, M. Viscerality, faith, and skepticism: another theory of magic. Hau: Journal of Ethnographic Theory, v. 6, n. 3, p. 453-483, 2016.

TINKER, H. A new system of slavery: the export of Indians overseas, 1830-1920. 2nd ed. London: Hansib, 1993.

WILLERSLEV, R. Soul hunters: hunting, animism, and personhood among the Siberian Yukaghirs. Berkeley: University of California Press, 2007.

WILLIAMS, B. Dutchman ghosts and the history mystery: ritual, colonizer, and colonized interpretations of the 1763 Berbice slave rebellion. Journal of Historical Sociololgy, v. 3, n. 2, p. 133-165, 1990.

WILLIAMS, B. Stains on my name, war in myveins: Guyana and the politics of cultural struggle. Durham: Duke University Press, 1991.

WIRTZ, K. Ritual, discourse, and community in Cuban santería: speaking a sacred world. Gainesville: University Press of Florida, 2007.

WIRTZ, K. Spirits materialities in Cuba folk religion: realms of imaginative possibility. In: BLANES, R.; ESPÍRITO SANTO, D. (ed.). The social life of spirits. Chicago: The University of Chicago Press, 2014. p. 126-156.

Recebido: 31/01/2019 Aceito: 24/06/2019 | Received:1/31/2019 Accepted:6/24/2019 